\title{
6.5 GHZ AND 10.2 GHZ PATH LOSS MEASUREMENTS AND MODELING FOR 5G COMMUNICATIONS SYSTEM PREDICTION
}

\author{
Nor Raihan Zulkefly ${ }^{1}$, Tharek Abdul Rahman ${ }^{2}$, Marwan Hadri Azmi ${ }^{3}$, Omar Abd. Aziz \\ ${ }^{1}$ Faculty of Electrical Engineering, Universiti Teknologi Malaysia, 81310, Johor, Malaysia \\ ${ }^{2}$ Faculty of Electrical Engineering, Universiti Teknologi Malaysia, 81310, Johor, Malaysia \\ ${ }^{3}$ Faculty of Electrical Engineering, Universiti Teknologi Malaysia, 81310, Johor, Malaysia \\ ${ }^{4}$ Faculty of Electrical Engineering, Universiti Teknologi Malaysia, 81310, Johor, Malaysia
}

\begin{abstract}
This paper presents the large-scale parameters of narrowband multipath channel propagation of corridor environments for the fifth generation $(5 G)$ communications system. The measurements were conducted on narrow, wide and open corridor structure in Universiti Teknologi Malaysia (UTM) Kuala Lumpur campus, Malaysia. Measurements campaign are conducted at $6.5 \mathrm{GHz}$ and $10.2 \mathrm{GHz}$, and path loss exponents (PLEs) and shadow fading are extracted using linear-least-square regression fitting from measured received-signal-strength (RSS). Furthermore, the results measurements campaign is modeled using well-known close-in reference distance (CI) and floating-intercept (FI) models. The result found in this work discovered the breakpoint distances (bps) of radio propagation are seen varies differently at those corridors for diverse frequencies.
\end{abstract}

Keywords: 5G, Indoor Corridor, Outdoor Corridor, Radio Propagation, Path Loss Models

\section{INTRODUCTION}

Currently, the demand for the high capacity and data rate are dramatically increasing, corresponding to the smartphones and communication devices advancement [1]. It is expected that mobile and wireless traffic volume will increase a thousand-fold over the next decade which will be driven by the expected billions of connected devices by 2020 and all need to access and share data, anywhere and anytime [2][4].

With the rapidly increasing number of connected devices, the challenges appear as corresponding to provide better user experience. As the current technology is severely causing to bandwidth shrunk and unable to cope the future mobile traffic, the routes to future generation $5 \mathrm{G}$ will be taken to fulfill the requirements [5].

The key to achieving high capacity of the 5G communications system, the technology has to move to the higher frequency band, specifically at centimeter-wave $(\mathrm{cm}-$ Wave) and millimeter-wave (mm-Wave), where the availability of bandwidth in the frequency bands. ITU-R has revealed the attention is drawing for potential frequency range for $5 \mathrm{G}$ communications, between $6 \mathrm{GHz}$ to $100 \mathrm{GHz}$ in WRC'15 for IMT-2020 [6]-[10]. As the existing channel characterization and modeling are evaluated for below 6 $\mathrm{GHz}$ [11], the application of the new spectrum bands requires specific characterization of network access.

There are existing and ongoing works characterizing 5G channel on cm-Wave and mm-Wave. For the case of corridors, the work in [12] presented the path loss (PL) models at $915 \mathrm{MHz}$ and $2.4 \mathrm{GHz}$, on the narrow, and wide corridor. The similar work conducted at $900 \mathrm{MHz}$ and 2.44
$\mathrm{GHz}$ studied the corridor reflection and diffraction mechanism. Moreover, the diffraction effects on the corridor were investigated in [13] by using MIMO antenna array.

A handful of corridor channel characterization was conducted at cm-Wave. As far as author's concern, channel characterization once conducted at $15 \mathrm{GHz}$ as presented in [14]. Due to the similar dimensional structure to the corridor, the range of studies was conducted to measure PL for line-of-sight (LOS) and non-line-of-sight (NLOS) in underground tunnel and mine environments [15][16][17].

To the author's best knowledge, there is none work literature studied the PL model on the different structure of corridor, particularly at $6.5 \mathrm{GHz}$ and $10.2 \mathrm{GHz}$. In this paper, the measurement-based channel propagation was conducted to evaluate and model PL and shadow fading, for a $5 \mathrm{G}$ communication system. Three types of corridors were measured, open structure outdoor corridor, narrow structure indoor corridor, and wide structure tunnel corridor.

The remainder of the paper is organized as follows. Measurement description and scenario are described in Section II and the PL models are presented in Section III. In Section IV, the numerical result and discussion are drawn, before the conclusion of the paper in Section V.

\section{MEASUREMENTS DESCRIPTION}

\subsection{Equipment Setup}

Narrow-band measurement campaigns were conducted at $28 \mathrm{GHz}$ for a range of $40 \mathrm{~m}$ to $100 \mathrm{~m}$ transmitter-toreceiver (T-R) separation distance. At the TX side, the continuous-wave ( $\mathrm{CW}$ ) of $9 \mathrm{dBm}$ unmodulated radio signal 
were generated by Anritsu MG369xC Signal Generator and delivered to pyramidal horn antenna of $12 \mathrm{dBi}$ antenna gain for $6.5 \mathrm{GHz}$ and $10.2 \mathrm{GHz}$ respectively. The TX antenna was mounted on a $2 \mathrm{~m}$ height above the floor on a wooden tripod. At the RX side, the omni-directional antenna of $3 \mathrm{dBi}$ antenna gain was mounted on the wooden tripod at $1.5 \mathrm{~m}$ height above the floor, and RSS was recorded using Anritsu MS2720T handheld spectrum analyzer (see Fig.1).

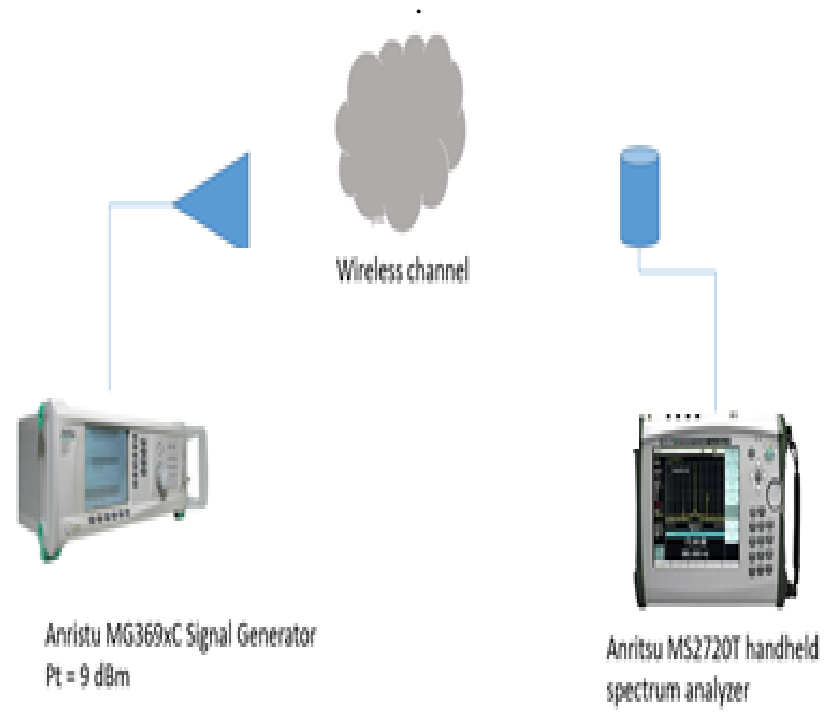

Fig 1: Measurement setup for channel characterization at 6.5 GHz and $10.2 \mathrm{GHz}$

\subsection{Environment and Measurement Procedure}

\section{Open Corridor}

The open corridor located outdoor, without wall enfold. The open corridor is constructed from metal zinc ceiling and covered by porcelain tile floor. Apart of that, the corridor is implanted with the permanent metal pole at every $1.5 \mathrm{~m}$, as depicted in Figure. The dimension of the open corridor is $3.5 \mathrm{~m}$ height, $2.5 \mathrm{~m}$ width, and $100 \mathrm{~m}$ length.

\section{Wide Corridor}

The wide corridor is a tunnel-like corridor, constructed of $30 \mathrm{~m}$ reinforced concrete walls and ceiling, while the corridor floor is covered by cement tile. The dimension of the wide corridor is $2.5 \mathrm{~m}$ height, $3.6 \mathrm{~m}$ width, and $60 \mathrm{~m}$ length. Furthermore, the corridor is built with openings structure particularly at $13 \mathrm{~m}$ (0.3 m width), $14 \mathrm{~m}$ (1 m width) and $15 \mathrm{~m}$ ( $1 \mathrm{~m}$ width) of the corridor.

\section{Narrow Corridor}

For narrow corridor, the corridor is located at 4th floor of Malaysia-Japan International Institute of Technology in UTM-Kuala Lumpur campus. The wall is enclosed by reinforced concrete wall, of $23 \mathrm{~cm}$ thickness, the ceiling is made of asbestos, and the floor is covered by porcelain tile. The dimension of the narrow corridor is $3.5 \mathrm{~m}$ height, 1.5 widths, and 40 lengths. The corridor structure as depicted in Figure 2 (a) to (c).
For this measurement campaigns, TX was kept stationary at one end of the corridor, while RX is a move for each $1 \mathrm{~m}$ adjacent away toward the end of another corridor side , to capture RSS at every $1 \mathrm{~m}$ distance. The repeated measurements are performed to obtain a precise value of RSS. The average of RSS was then used to compute the PL and shadow fading, and hence the PLEs are further extracted. To verify the measured results, the measurements campaign were conducted repeated, where the TX and RX are aligned to each other boresight. Moreover, the measurements campaign were conducted during the offhour, to avoid human induce and movement interference.

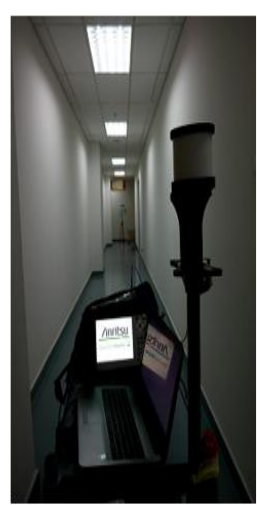

a

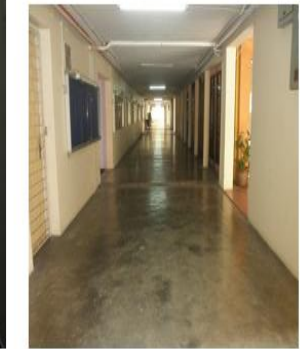

b

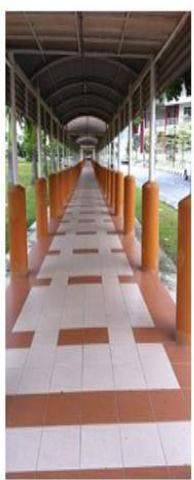

C
Fig 2: The construction of (a) narrow corridor, (b) wide corridor and (c) open corridor.

\section{6.5 GHZ AND 10.2 GHZ PATH LOSS MODELS FOR CORRIDORS}

The CI path loss model is presented as statistical path loss model of a single frequency, which is derived from the measurement dataset and as is shown as follow:

$$
P L^{C I}[d B]=P L_{d_{0}}+10 n \log _{10}\left(\frac{d}{d_{0}}\right)+\chi_{\sigma}^{C I}
$$

where $P L_{d_{0}}$ is the free-space reference distance at $d_{0}=1 \mathrm{~m}$, $\mathrm{d}$ is the distance of 3-D TX-RX separation, $\mathrm{n}$ is the path loss exponent parameter that derived from least-square error approach which fits the measurement data, and $X \sigma^{C I}$ is a zero-mean Gaussian random variable with standard deviation $\sigma$ in decibels.

Another path loss model is called the floating-intercept (FI) path loss model which used in the WINNER II and 3GPP standards [18][19]. It is based on the floating-intercept ( $\alpha$ ) and line slope ( $\beta$ ) to provide the best minimum error fit of collected path losses as follows: 


$$
P L^{F I}[d B]=\alpha+10 \cdot \beta \log _{10}(d)+\chi_{\sigma}^{F I}
$$

Where $\chi_{\sigma}^{F I}$ is a zero mean Gaussian (in $\mathrm{dB}$ ) shadow fading random variable, which describes large-scale signal fluctuations about the mean PL over distance.

\section{RESULT AND DISCUSSION}

The following Figure 3 to Figure 8 provide the measured and models parameterization of PL and shadow fading obtained for three differently dimensional corridors at 28 $\mathrm{GHz}$.

\subsection{Measurement Results}

The range of measured PL is observed lowest for the narrow corridor from $35 \mathrm{~dB}$ to $75 \mathrm{~dB}$, compared to $40 \mathrm{~dB}$ to $90 \mathrm{~dB}$ and $45 \mathrm{~dB}$ to $100 \mathrm{~dB}$ for wide and open corridor at $6.5 \mathrm{GHz}$ and $10.2 \mathrm{GHz}$. respectively. The variation of PL lowest at narrow corridor due to the higher constructive multipath reflection of embedded environment. For wide corridor, the multipath reflection is lowest and cause to deconstructive fading due to opening sections of the corridor. On the other hand, the PL is severe in the open corridor, as low multipath reflection occurs within the semi-embedded area as such.

Moreover, the result of linear fitting show 1.33, 1.66 and 1.92 PLEs are computed for narrow, wide and open corridors respectively. The high PL at open corridor shows nearly to free-space PLE as worst radio wave reflection exist in open corridor. Otherwise, the thinner and enclosed structure environments improve the radio frequency (RF) transmission as indicated by PLE of narrow and wide corridors. The lower than free-space (PLE is 2) in the corridors, attributes to the waveguide phenomenon within the corridors

The correctional factor $(\mathrm{Fc})$ for three corridors is observed, indicates high $\mathrm{Fc}$ is seen for narrow corridor approximately $20 \mathrm{~dB}$ and $15 \mathrm{~dB}$ at $6.5 \mathrm{GHz}$ and $10.2 \mathrm{GHz}$. On the other hand, $5 \mathrm{~dB}$ and $8 \mathrm{~dB} \mathrm{Fc}$ is perceived for the wide corridor, while $6 \mathrm{~dB}$ and $5 \mathrm{~dB}$ for open corridor at $6.5 \mathrm{GHz}$ and 10.2 $\mathrm{GHz}$ respectively. We agree the Fc represent a considerable range of multipath reflection constructively or destructively attenuates the RF on LOS straight corridor environment.

For the case of shadow fading, it can be observed that shadow fading is not only relatively dependent on environments but also frequency. $6.5 \mathrm{GHz}$ indicate the range of shadow fading from $5 \mathrm{~dB}$ to $8 \mathrm{~dB}$, while slightly higher multipath fading observed at $10.2 \mathrm{GHz}$ of $6.3 \mathrm{~dB}$ to $9 \mathrm{~dB}$ for all corridors respectively.

The propagation mechanism in this work involved a different range of dbp, at different corridors and frequencies. As the longer distance of $\mathrm{dbp}$ is seen on narrow corridor of $32 \mathrm{~m}$ and $25 \mathrm{~m}$ for $6.5 \mathrm{GHz}$ and $10.2 \mathrm{GHz}$. For the case of wide and open corridor, dbps are seen $29 \mathrm{~m}$ to $25 \mathrm{~m}$, and $25 \mathrm{~m}$ to $22 \mathrm{~m}$ for $6.5 \mathrm{GHz}$ and $10.2 \mathrm{GHz}$ respectively. These results associate two-fold of finding, first, the narrower environments able to extend the RF propagation longer than wider or open environments and second is the $\mathrm{dbp}$ is can be evaluated for less than $1 \mathrm{~km}$ transmission distance for higher frequency bands (in this work maximum transmission distance is $100 \mathrm{~m}$ ).

\section{Narrow Corridor}

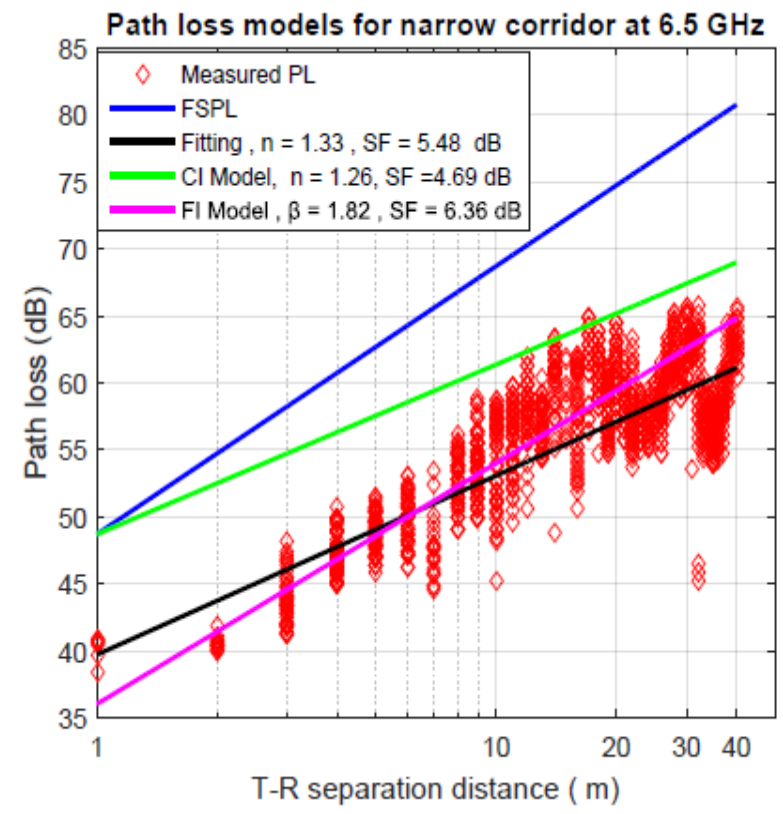

Fig 3: Path loss models for narrow corridor at $6.5 \mathrm{GHz}, \mathrm{dbp}$ $=32 \mathrm{~m}, \mathrm{Fc}=20 \mathrm{~dB}$

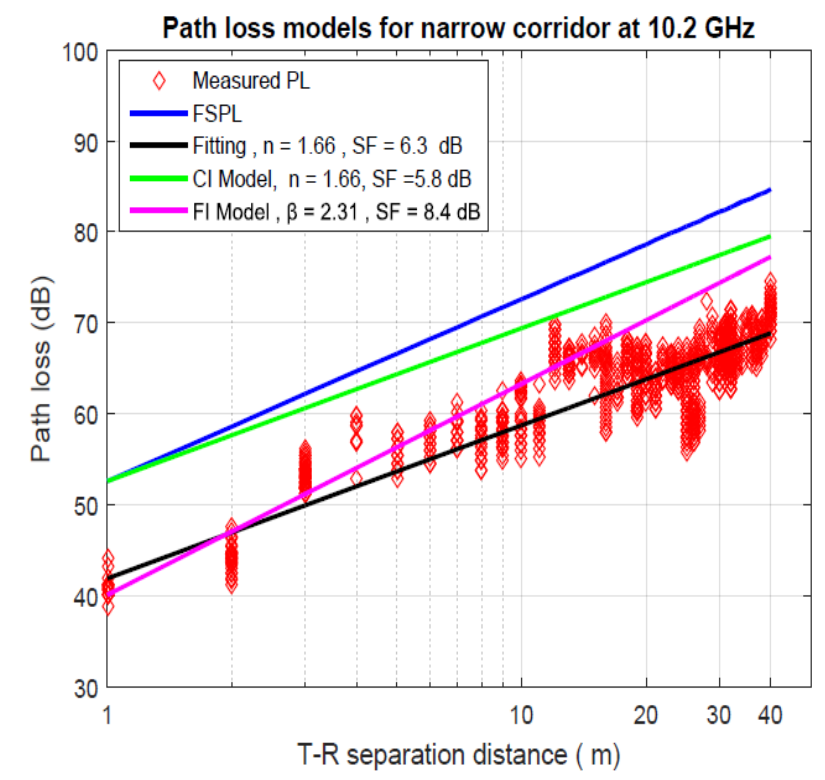

Fig 4: Path loss models for narrow corridor at $10.2 \mathrm{GHz}$, $\mathrm{dbp}=25 \mathrm{~m}, \mathrm{Fc}=15 \mathrm{~dB}$ 


\section{Wide Corridor}

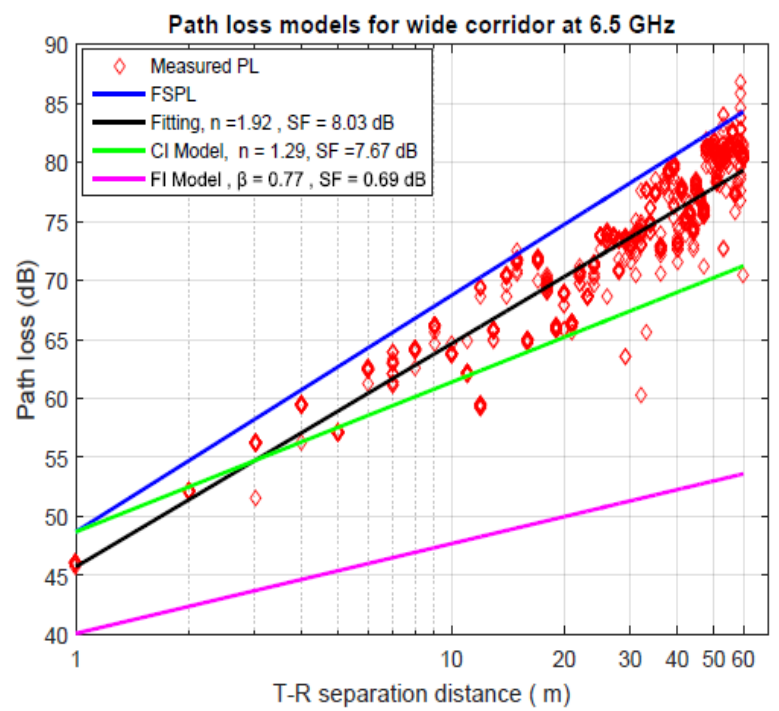

Fig 5: Path loss models for wide corridor at $6.5 \mathrm{GHz}, \mathrm{dbp}=$ $29 \mathrm{~m}, \mathrm{Fc}=5 \mathrm{~dB}$

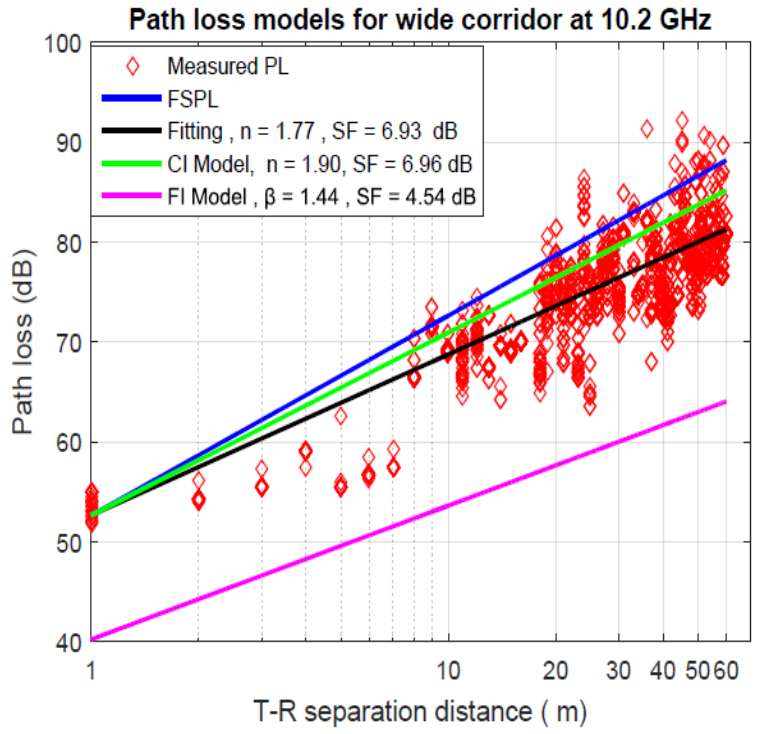

Fig 6: Path loss models for wide corridor at $10.2 \mathrm{GHz}$, dbp $=25 \mathrm{~m}, \mathrm{Fc}=8 \mathrm{~dB}$

\section{Open Corridor}

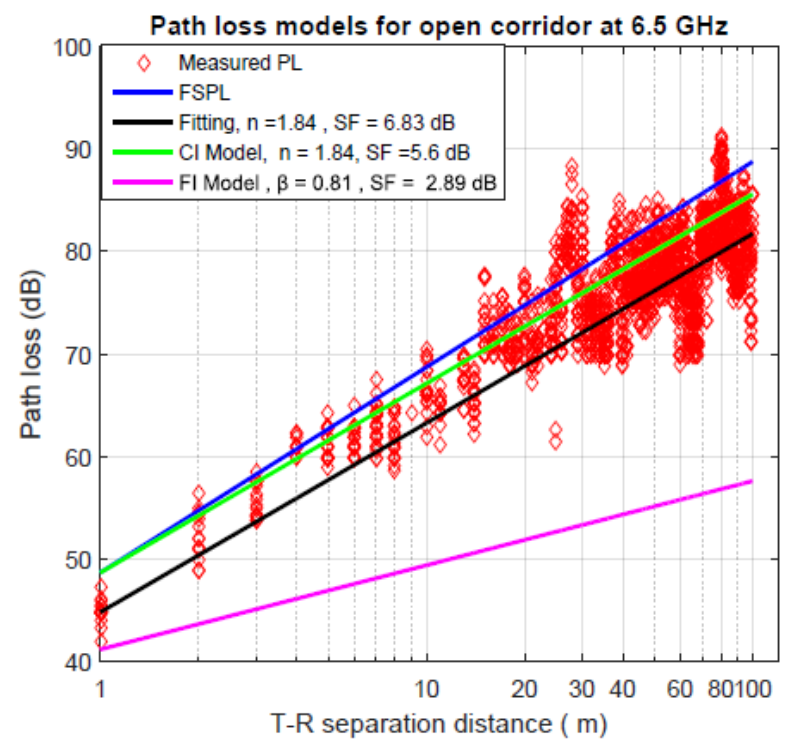

Fig 7: Path loss models for open corridor at $6.5 \mathrm{GHz}, \mathrm{dbp}=$ $25 \mathrm{~m}, \mathrm{Fc}=6 \mathrm{~dB}$

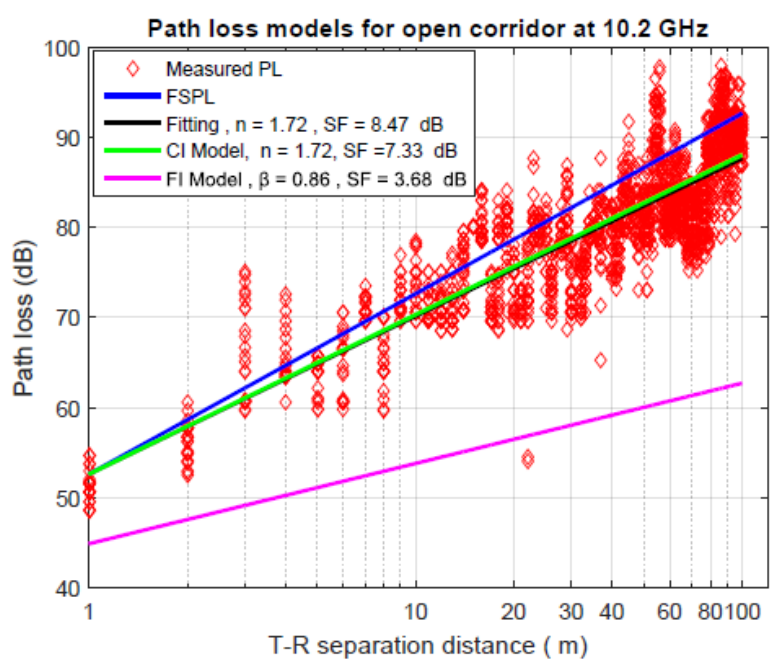

Fig 8: Path loss models for open corridor at $10.2 \mathrm{GHz}$, dbp $=22 \mathrm{~m}, \mathrm{Fc}=5 \mathrm{~dB}$

\subsection{Path Loss Models Analysis}

Table 1 provides the path loss parameters for CI and FI respectively. The path loss and shadow fading models are presented in term of frequency-dependent to describe channel characterization at $6.5 \mathrm{GHz}$ and $10.2 \mathrm{GHz}$.

PLEs shown on CI model are nearly similar to linear fitting on the measured PL, range between 1.26 to 1.90 . The lower than 2 PLEs indicate the great waveguide occur of the environments, succinctly happen at the narrow corridor. On the other hand, high PLEs at open corridor indicate degrading of a channel waveguide and higher RF attenuation. It is noted that the shadow fading for all corridors range between $4 \mathrm{~dB}$ to $8 \mathrm{~dB}$ and seen smallest at 
the narrow corridor. The shadowing value is typical for indoor or closed environments.

In FI models, $\alpha$ is seen low from the measured linear fitting, range between $36.04 \mathrm{~dB}$ to $44.91 \mathrm{~dB}$. Equally to $\beta$, the values observed are widely varied compared to measured PLEs. This is a consequence of no physical basis estimation approach of FI model, compared to CI model. For shadow fading, FI estimate slightly low shadowing compared to CI models.

Table- 1: Path loss models parameters for open, wide and narrow corridors at $6.5 \mathrm{GHz}$ and $10.2 \mathrm{GHz}$

\begin{tabular}{|l|l|l|l|l|}
\hline CI Path loss models parameters & \multicolumn{3}{|l|}{} \\
\hline Freq (GHz) & Corridor & PLdo (dB) & PLE & $\begin{array}{l}\text { Shadow fading } \\
\text { (dB) }\end{array}$ \\
\hline \multirow{3}{*}{6.5} & Narrow & 48.7 & 1.26 & 4.69 \\
\cline { 2 - 5 } & Wide & 48.7 & 1.29 & 7.67 \\
\cline { 2 - 5 } & Open & 48.7 & 1.84 & 5.6 \\
\hline \multirow{3}{*}{10.2} & Narrow & 52.62 & 1.66 & 5.8 \\
\cline { 2 - 5 } & Wide & 52.62 & 1.90 & 6.96 \\
\cline { 2 - 5 } & Open & 52.62 & 1.72 & 7.32 \\
\hline
\end{tabular}

FI Path loss models parameters

\begin{tabular}{|l|l|l|l|l|}
\hline \multirow{2}{*}{ Freq $(\mathrm{GHz})$} & Corridor & $\alpha(\mathrm{dB})$ & $\beta$ & $\begin{array}{l}\text { Shadow fading } \\
(\mathrm{dB})\end{array}$ \\
\hline \multirow{4}{*}{6.5} & Narrow & 36.04 & 1.82 & 6.36 \\
\cline { 2 - 5 } & Wide & 40.6 & 0.77 & 0.69 \\
\cline { 2 - 5 } & Open & 42.01 & 0.81 & 2.89 \\
\hline \multirow{3}{*}{10.2} & Narrow & 40.1 & 2.31 & 8.4 \\
\cline { 2 - 5 } & Wide & 40.2 & 1.44 & 4.54 \\
\cline { 2 - 5 } & Open & 44.91 & 0.89 & 3.68 \\
\hline
\end{tabular}

\section{CONCLUSION}

This paper presents narrowband channel characterization at 6.5 $\mathrm{GHz}$ and $10.2 \mathrm{GHz}$. Three differently dimension corridors are a measured, narrow, wide and open corridor. The channel characterization is modeled using well-known path loss model, CI and FI models, where the path loss exponent and shadow fading are extracted from measured PL. Beside path loss and shadow fading parameters, the dbp and $\mathrm{Fc}$ are also evaluated. These channel measurements and modeling result will benefit to $5 \mathrm{G}$ channel model, especially to estimate the signal coverage and RF transmission for corridors.

\section{REFERENCES}

[1] D. Kurita, K. Tateishi, A. Harada, and Y. Kishiyama, "Indoor and Outdoor Experiments on 5G Radio Access Using Distributed MIMO and Beamforming in $15 \mathrm{GHz}$ Frequency Band," vol. 1200, no. Cc, pp. 5-10, 2016.

[2] Osseiran, V. Braun, and T. Hidekazu, "The foundation of the mobile and wireless communications system for 2020 and beyond," Proc. IEEE Veh. Tech. ..., pp. 1-5, 2013.

[3] Gupta and R. K. Jha, "A Survey of 5G Network: Architecture and Emerging Technologies," IEEE Access, vol. 3, pp. 1206-1232, 2015.

[4] Osseiran, F. Boccardi, V. Braun, K. Kusume, P. Marsch, M. Maternia, O. Queseth, M. Schellmann, H. Schotten, H. Taoka, H. Tullberg, M. A. Uusitalo, B. Timus, and M. Fallgren, "Scenarios for 5G mobile and wireless communications: The vision of the
METIS project," IEEE Commun. Mag., vol. 52, no. 5, pp. 26-35, 2014.

[5] L. WEI, A. G. ROSE QINGYANG HU, YI QIAN, and Lili, "Key elements to enable millimeter wave communications for 5G wireless systems," IEEE Wirel. Commun., vol. 21, no. 6, pp. 136-143, 2014.

[6] R. Bureau, "Preparations for Purpose of ITU WRCs."

[7] Circular and R. S. Members, "Radiocommunication Bureau ( BR )," no. August, pp. 1-51, 2015.

[8] U. Löwenstein, "ITU-R activities towards 5G between WRC-15 and WRC-19," no. July, 2016.

[9] R. Marks and E. Associates, "IEEE 802 5G Spectrum Considerations," https://mentor.ieee.org/802ec/dcn/16/ec-16-0068-00-5GSG-ieee-802-5gspectrum-considerations.pdf, 2016.

[10] D. Summit, "Verticals and 5G Evolution," 2016.

[11] N. T. T. Docomo, "5G Channel Model for bands up to $100 \mathrm{GHz}, " 2016$.

[12] T. R. Rao and D. Balachander, "RF Propagation Investigation at $915 / 2400 \mathrm{MHz}$ In Indoor Corridor Environments for Wireless Sensor Communications," Prog. Electromagn. Res. B, vol. 47, no. October 2012, pp. 359-381, 2013.

[13] N. Lertwiram, G. K. Tran, K. Mizutani, K. Sakaguchi, and K. Araki, "MIMO radio propagation measurement for two-hop relay network on L-shaped corridor with network performance analysis," IEEE Veh. Technol. Conf., 2010.

[14] Zhang, Z. Zhong, X. Zhou, K. Guan, and R. He, "Path Loss Characteristics of Indoor Radio Channels at $15 \mathrm{GHz}$," in 2016 10th European Conference on Antennas and Propagation (EuCAP), 2016. 
[15] Hrovat, G. Kandus, and T. Javornik, "Path loss analyses in tunnels and underground corridors," Int. J. Commun., vol. 6, no. 3, pp. 136-144, 2012.

[16] Nkakanou, G. Y. Delisle, and N. Hakem, "Experimental evaluation of the ultra-wideband propagation channel in an underground mine," IEEE Antennas Propag. Soc. AP-S Int. Symp., pp. 27812784, 2011.

[17] M. Boutin, A. Benzakour, C. L. Despins, and S. Affes, "Radio wave characterization and modeling in underground mine tunnels," IEEE Trans. Antennas Propag., vol. 56, no. 2, pp. 540-549, 2008.

[18] P. Jesus, C. Silva, A. Mihovska, S. Kyriazakos, K. Pantelis, K. George, Y. Zhu, and Y. Wan, "IST-4027756 WINNER II,” vol. 1, no. 42, pp. 1-42, 2007.

[19] E. Seidel and C. T. Officer, "3GPP LTE-A Standardisation in Release 12 and Beyond," no. January, pp. 1-9, 2013.

\section{BIOGRAPHIES}

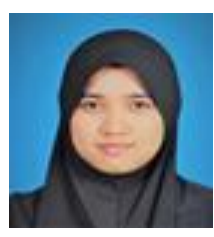

Nor Raihan Zulkefly (Student, IEEE) obtained her Bachelor Degree of Data Communication in 2010. In 2012 she obtained her MEng. in Electrical/ Electronic and System majoring in Computer and Communication from National University of Malaysia (UKM). Currently she pursues her study as PhD. candidate in Universiti Teknologi Malaysia (UTM). Her research interest is include but not limited to wireless radio propagation in $5 \mathrm{G}$.

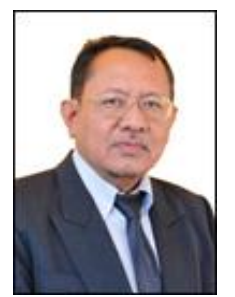

Tharek Abd Rahman (Member, IEEE) is a Professor at Faculty of Electrical Engineering, Universiti Teknologi Malaysia (UTM). He obtained his BSc. in Electrical \& Electronic Engineering from University of Strathclyde UK in 1979, MSc in Communication Engineering from UMIST Manchester UK and PhD in Mobile Radio Communication Engineering from University of Bristol, UK in 1988. He is the Director of Wireless Communication Centre (WCC), UTM. His research interests are radio propagation, antenna and RF design and indoors and outdoors wireless communication. He has published more than 300 papers related to wireless communication in national/international journal and conference.

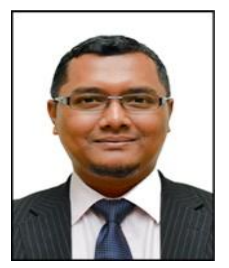

Omar Abdul Aziz (Member IEEE) received his first degree in 2006 from Universiti Teknologi Petronas, Malaysia in the field of Electrical \& Electronics Engineering. He was a Research Assistant and later appointed Tutor in Wireless Communication Centre (WCC). In 2009, he received his Master Degree in Electrical-Electronics \& Telecommunication Engineering from Universiti Teknologi Malaysia (UTM). His research interests are antenna design and microwave propagation.

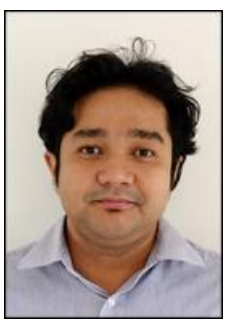

Marwan Hadri Azmi received the B.Eng. (Hons Class I) degree in electrical and telecommunications from the Universiti Teknologi Malaysia in 2003, the M.Sc. degree in communications and signal processing from the Imperial College of Science, Technology and Medicine, University of London in 2005, and the Ph.D. degree from the University of New South Wales, Australia, in 2012. He is currently a senior lecturer at Wireless Communication Centre, Universiti Teknologi Malaysia. From 2012 to 2014, he spent his Sabbatical leave of absence at the McGill University, Canada, working in the funded project by RIM Inc. and NSERC, entitled "Cooperative Spectrum Sensing and Information Relaying in Cognitive Wireless Communications". His research interests include mobile and wireless communications, communication theory, error control coding, relay networks, spectrum sensing for cognitive radio, and iterative receiver. 